\title{
CAMBIAR HACIA LO ÉTICO
}

CPC Félix Armando Pariona Garcia*

Muchas veces nosotros hablamos en estos tiempos "se están perdiendo los valores, dónde está la moral y ética de las personas". A diario leemos titulares que abordan el tema y nos bombardean de noticias en todo aspecto, pero nosotros nos preguntamos: ¿qué es lo que realmente significa?

\section{¿Qué es la êtica?}

El término ética se ha definido como el estudio de la forma en que nuestras decisiones afectan a los demás. También es el estudio de los derechos y las obligaciones de las personas, de las reglas morales que las personas aplican cuando toman decisiones y de la naturaleza de las relaciones entre personas.

\section{Instrumentos de la ética}

Todos hacemos algún tipo de razonamiento ético, sea consciente o inconscientemente, todos los días de nuestra existencia. Para que mejore nuestro razonamiento ético debemos analizarlo en forma explícita y practicarlo todos los días. Los términos básicos del lenguaje de la ética son valores, derechos, obligaciones, reglas y relaciones.

Analicemos cada uno de ellos.

\section{Valores}

Cuando valora algo o lo quiere tener o quiere que ocurra. Los valores son deseos, relativamente permanentes, que parecen buenos en sí, como la paz o la buena voluntad.

Los valores responden a la pregunta ¿por qué? ¿Por qué usted paga impuestos? Quizá responda que es porque quiere contribuir con el país. ¿Por qué es importante que lo haga?

Para poder ayudar a mi comunidad en la construcción de puentes, carreteras, hospitales, etc.

De los valores depende que llevemos una vida grata, alegre, en armonía con nosotros mismos y con los demás; una vida que valga la pena ser vivida y en la que podamos desarrollarnos plenamente tanto como profesionales y como personas.

¿Para qué sirven los valores morales dentro de nuestra profesión?

Los valores morales son los que orientan nuestra conducta en nuestra vida y los aplicamos también en nuestros quehaceres profesionales a lo largo del desarrollo de nuestras actividades; sobre la base de ellos decidimos

\footnotetext{
* Alumno de Maestria-Unidad de Postgrado.
} 
cómo actuar ante las diferentes situaciones que nos plantea la vida profesional. Se relacionan principalmente con los efectos que tiene lo que hacemos en las otras personas, en nuestros hogares, en nuestra sociedad, en nuestro pais.

De esta manera si deseamos vivir y ser felices debemos construir entre todos una escala de valores que facilite nuestro crecimiento personal para que, a través de él, aportemos lo mejor de nosotros hacia nuestra comunidad.

\section{Derechos y obligaciones}

Un derecho otorga a la persona el "espacio" que necesita para actuar. En têrminos más formales, cabría llamar a este espacio el "ámbito de la autonomia" de la persona, o más sencillo aún, su libertad. Los derechos rara vez son absolutos; la mayoria de las personas admitiria que el alcance de los derechos individuales llega hasta el punto donde empiezan los derechos de los demás. Por regla general uno tiene derecho a decir libremente lo que piensa, mientras no se viertan calumnias contra otra persona.

Los derechos están en relación directa con las obligaciones. Cuando una persona tiene un derecho, otra tiene una obligación al respecto. Una obligación es el deber de dar pasos concretos, por ejemplo, pagar impuestos y respetar la ley en todos los sentidos.

\section{Reglas morales}

Las reglas morales nos sirven de guia para situaciones en las que chocan intereses contrapuestos.
Valdria decir que las reglas morales son como "rompeolas"; es decir, lineamientos que pueden resolver desacuerdos. Las reglas morales, que son reglas de la conducta, muchas veces se asimilan con valores.

\section{Relaciones Humanas}

Todo ser humano está relacionado con otros mediante una madeja de relaciones. Estas relaciones existen porque unos y otros nos necesitamos para recibir apoyo y para alcanzar nuestras metas. Desde la relación de un niño con sus padres hasta la relación de un gerente con un empleado, las relaciones representan un aspecto generalizado de la vida de orden moral. Constantemente estamos decidiendo como conservarlas y alimentarlas. Estas decisiones reflejan nuestros valores y nuestro interés por la ética.

\section{Orden Moral}

El orden moral constituye el cuerpo de las reglas morales que rige los problemas normales de la ética. Se trata de las reglas que aplicamos a la vida, la mayoría de las veces, y que podemos usar para entender los problemas de la contabilidad en término de la ética. Repasemos brevemente algunos principios básicos del orden moral par ver cómo funcionan.

\section{Promesas cumplidas}

Casi todas las personas quieren estar seguras de que los demás cumplirán su palabra. Si no existiera la simple convención de las 
promesas cumplidas, la interacción social se detendría en seco, los negocios serían imposibles. Por consiguiente, toda teoria moral afirma, cuando menos, que los seres humanos deben respetar la mayor parte de sus promesas, la mayoría de las veces. Los negocios turbios al interior fueron de tal magnitud, en parte, porque las personas que cometieron el ilicito habían prometido que no realizarian dichas actividades.

\section{Buena fe y confianza}

Entre otras cosas, los derechos y las obligaciones son una forma de evitar los conflictos violentos. Si tuviéramos que preocuparnos constantemente por nuestra seguridad física fundamental, estariamos mucho menos dispuestos a confiar en los demás y a participar en tratos complejos que pueden implicar disputas con ellos. Por consiguiente, la mayor parte de las teorias requiere que la mayoría de las personas, la mayor parte de las veces, evite hacerle daño a otros seres humanos.

\section{Ayuda reciproca}

Las comunidades humanas se sustentan en reconocer que unas personas dependen de otras y unas personas ayudan a otras. Las donaciones que hacen las empresas al IPD para fomentar el deporte son un buen ejemplo. De acuerdo con el principio de la ayuda reciproca, las personas se deben ayudar unas a otras, si el costo por hacerlo no es demasiado grande.

\section{Respeto por las personas}

El orden moral también exige que consideremos que los demás son un fin en sí y no un mero medio para alcanzar nuestros fines. El hecho de tratar a las personas como si fueran fines implica tomarlas en serio, aceptar que sus intereses son legítimos y considerar que sus deseos son importantes.

\section{Respeto por la propiedad}

El concepto de la propiedad se sustenta en el principio de que la mayoria de las personas, la mayoría de las veces, debe obtener el consentimiento de otros para usar sus bienes. Si usted piensa que las personas son dueñas de su cuerpo, el respeto por los bienes es un corolario del respeto por las personas.

\section{Código de Ética profesional}

Las normas contenidas en el presente Código de Ética buscan normar el buen desempeño de los profesionales Contadores Públicos y se aplican a los miembros de los colegios profesionales del país.

Este código norma la conducta del Contador Público en el ejercicio de la profesión sea cual fuere dependiente e independiente; así como también, la conducta con sus colegas.

Dentro de las normas generales en el ejercicio profesional menciona que el Contador Público deberá actuar con probidad y buena fe, manteniendo el honor, dignidad y 
capacidad profesional, observando las reglas de ética más elevadas en todos sus actos.

El Contador Público no podrá hacer declaraciones públicas en contra de la institución, ni participar de actos que sean lesivos a la profesión.

El Contador Püblico asumirá su responsabilidad con relación a sus informes, dictámenes, declaraciones juradas, etc., refrendados con su firma. No podrá retener información de sus clientes sean libros, documentación sea cual fuere la causa, por tratarse de una apropiación indebida.

El Contador Público tiene la obligación de guardar el secreto profesional, es decir, el de no revelar por ningún motivo los hechos, datos o circunstancias de los que tenga conocimiento en el ejercicio de su profesión, excepto por las informaciones que obligan las disposiciones legales.

Tampoco podrá beneficiarse haciendo uso de la información que obtenga en el ejercicio de la profesión ni podrá divulgar a otras personas con el mismo fin; no podrá revelar datos que identifiquen a las personas o negocios a menos que se le autorice.

El Contador Público en el desempeño de su función debe mantener independencia de criterio, es decir, no dejarse llevar por sentimientos, ni susceptibilidades ofreciendo así el mayor grado de objetividad e imparcialidad donde se desempeñe basándose en hechos debidamente comprobables en aplicación de los principios de contabilidad y las normas contables
(NIC's) y de auditoria (NIA's) y las técnicas contables aprobadas por la profesión en los congresos nacionales e internacionales.

El Contador Público debe tener presente que su actuación profesional conduce a tomar decisiones que repercuten hacia terceros, por lo que al emitir sus opiniones debe hacerlo con independencia de criterio.

En cuanto a la relación entre colegas el Contador Público podrá asociarse con otros colegas para el ejercicio profesional, de acuerdo a los dispositivos vigentes; no pudiendo ser socio de más de una Sociedad de Contadores Públicos.

El Contador Público deberá abstenerse de hacer juicios, de emitir opiniones o comentarios sobre la intervención profesional de otro colega.

En las sociedades de profesionales sỏlo podrán suscribir o refrendar informes y estados financieros quienes poseen título de Contador Público otorgado por una Universidad Peruana o revalidado en ella y debidamente colegiado e inscrita la sociedad en el registro que le corresponda.

El Contador Público podrá ejercer su actividad tanto: en forma dependiente, o independiente; cuando asume el compromiso de prestar sus servicios debe determinar el monto de sus honorarios, tomando como referencia, así como la responsabilidad que asume, la importancia de la empresa y otros factores, de tal manera que dicha base no resulte lesiva a la dignidad profesional. 


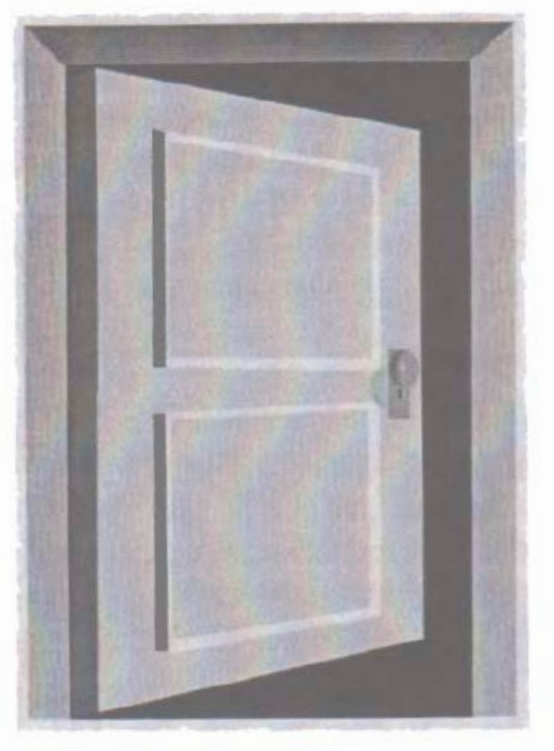

\section{BIBLIOGRAFÍA}

1. Stoner, James A.F., Freeman, R. Edward y Gilbert Jr.Daniel R. Administración, Edit. Prentice Hall Hispanoamericana S.A., $6^{a}$ ed., 1996. México.
"La puerta está abierta, para aquellos que se atreven a realizar verdaderos cambios, todo radica en tomar la decisión de hacerlo y aplicarlo en uno mismo».

"En la medida en que el hombre pueda verse como un ser lleno de valores, crecerá seguro y fortalecerá las posibilidades de ser feliz"
2. Federación de Colegios de Contadores Públicos del Perú y su Junta de Decanos. Código de Etica Profesional. Octubre, 1998 - Perú.

3. Empresa Editora El Comercio. "El Libro de los Valores". Revista Semanal. 